Pacific Journal of Mathematics

OSCILLATION CRITERIA FOR SELFADJOINT ELLIPTIC 


\title{
OSCILLATION CRITERIA FOR SELFADJOINT ELLIPTIC EQUATIONS
}

\author{
Kurt Kreith and Curtis C. Travis
}

\begin{abstract}
This paper extends several of the classical oscillation criteria for the Sturm-Liouville equation $\left(a u^{\prime}\right)^{\prime}+c u=0$ to selfadjoint elliptic equations of the form
\end{abstract}

$$
\sum_{i, j=1}^{n} \frac{\partial}{\partial x_{j}}\left(a_{i j}(x) \frac{\partial u}{\partial x_{j}}\right)+c(x) u=0 .
$$

Oscillation criteria for selfadjoint second order elliptic equations have been established by several authors [6], [3], and [4], generalizing the classical theory for Sturm-Liouville equations. The specific oscillation criteria of these studies have been stated in terms of functions which are pointwise majorants and minorants of the coefficients of an elliptic equation which arise naturally by separation of variables in various coordinate systems. Thus, for example, while Swanson and Headley [3] establish oscillation criteria of "limit type" and "integral type", the limit and integral tests must be applied to pointwise majorants and minorants which may not accurately reflect the limit or integral behavior of the coefficients of the equation under study.

In the present paper we establish oscillation criteria for elliptic equations in terms of majorants and minorants obtained by an averaging process. Specifically, in $\S 2$ an ordinary differential equation is derived which, if oscillatory at $\infty$, implies oscillatory behavior for $\Delta u+c(x) u=$ 0 in $E^{n}$. Applying an integral oscillation criterion to this ordinary differential equation leads to results such as the following

(Theorem 3.1): if $\iint_{E^{2}} c(x, y) d x d y=\infty$, then $\Delta u+c u=0$ is nodally oscillatory in $E^{2}$.

The elliptic equations under study will be of the form

$$
\sum_{i, j=1}^{n} \frac{\partial}{\partial x_{j}}\left(a_{i j} \frac{\partial u}{\partial x_{i}}\right)+c(x) u=0
$$

where $c(x)$ is continuous and the $a_{i j}(x)$ are of class $C^{1}$ in $E^{n}$. Points in $E^{n}$ are denoted by $x=\left(x_{1}, \cdots, x_{n}\right)$, and $|x|=\sqrt{x_{1}^{2}+\cdots+x_{n}^{2}}$. We define $E_{R}=\left\{x \in E^{n}:|x|>R\right\}$, and if $G$ is a domain in $E^{n}$, then $G_{R}=$ $G \cap E_{R}$.

The elliptic equation (1.1) is said to be nodally oscillatory in $E^{n}$ if for every $R>0$ there is a domain $G \subset E_{R}$ such that $G$ is a nodal domain for a solution of (1.1). By the Sturmian comparison theorem 
for elliptic equations (see for example [7]), if (1.1) is nodally oscillatory in $E^{n}$, then any global solution of (1.1) has a zero in every $E_{R}$.

Our basic tool, Theorem 2.2, is established in $\S 2$ below. In $\S 3$ we apply this Theorem to $\Delta u+c u=0$ in the case $n=2$ by exploiting known oscillation criteria for Sturm-Liouville equations of the form $\left(p v^{\prime}\right)^{\prime}+q v=0$ where $\int^{\infty} 1 /(p(x)) d x=\infty$. In case $n>2$ we are led to Sturm-Liouville equations for which $\int^{\infty} 1 /(p(x)) d x<\infty$, and this case is considered in $\S 4$. More general elliptic equations of the form (1.1) and (1.2) are considered in $\S 5$, while $\S 6$ is devoted to oscillation criteria for $\Delta u+c u=0$ in unbounded domains.

2. The related ordinary differential equation. Our principal tool is based on a special case of a theorem due to D. O. Banks [1]. Considering a nonnegative real valued function $\varphi(x)$ which is defined and measurable on a domain $G \subset E^{n}$, we define

$$
G(y)=\{x: \varphi(x) \geqq y\} .
$$

Theorem 1 of [1] then implies the following

THEorem (Banks) 2.1. If $f(x)$ is continuous in $G$ and satisfies

$$
\int_{G(y)} f(x) d x \geqq 0
$$

for all $y \in[0, \infty)$, then

$$
\int_{G} f(x) \varphi(x) d x \geqq 0 .
$$

REMaRk. While Banks proved Theorem 1 of [1] in $E^{2}$, his method of proof works equally well in $E^{n}$.

Consider now the equation

$$
\Delta u+c(x) u=0 \quad \text { in } E^{n}
$$

where $c(x)$ is continuous in $E^{n}$. Letting $(r, \theta)$ denote hyperspherical coordinates for $E^{n}$, volume integrals over annular regions can be written in the form

$$
\int_{r_{1}}^{r_{2}}\left[\int_{\Omega} f(r, \theta) d \theta\right] r^{n-1} d r
$$

where $\Omega$ denotes the full range of the angular coordinates. Letting

$$
\Sigma_{n}=\int_{\Omega} d \theta
$$


denote the area of the unit sphere in $E^{n}$, we define

$$
\gamma(r)=\frac{1}{\sum_{n}} \int_{\Omega} c(r, \theta) d \theta
$$

It follows readily from this definition that

$$
\int_{\Omega}[c(r, \theta)-\gamma(r)] d \theta=0
$$

for $0 \leqq r<\infty$. Our principal tool is the following.

THEOREM 2.2. If the ordinary differential equation

$$
\frac{d}{d r}\left(r^{n-1} \frac{d v}{d r}\right)+r^{n-1} \gamma(r) v=0
$$

is oscillatory at $r=\infty$, then (2.1) is nodally oscillatory in $E^{n}$.

Proof. Consider the equation

$$
\Delta v+\gamma(r) v=0
$$

where $\gamma(r)$ is defined as above. Equation (2.4) has solutions $v(r)$ which are independent of $\theta$, and these can be found by solving (2.3). If (2.3) is oscillatory, then there exists a function $v_{1}(r)$ which satisfies (2.4) and has a sequence of annular nodal domains determined by the zeros of $v_{1}(r), r_{1}<r_{2}<\cdots$ where $\lim _{k \rightarrow \infty} r_{k}=\infty$. In each annular nodal domain $G_{(k)} \equiv\left\{(r, \theta): r_{k-1}<r<r_{k}\right\}$, the function $v_{1}(r)$ is the first eigenfunction of

$$
\begin{aligned}
\Delta v+\gamma(r) v+\mu v & =0 & & \text { in } G_{(k)} \\
v(r, \theta) & =0 & & \text { on } \partial G_{(k)}
\end{aligned}
$$

corresponding to $\mu_{1}=0$. Furthermore the level curves (surfaces) of $v_{1}^{2}$ are circles (spheres). Therefore if $\varphi(x)=v_{1}^{2}(x)$ in Theorem 2.1 and

$$
G_{(k)}(y)=\{x: \varphi(x) \geqq y\}
$$

then by (2.2)

$$
\int_{G_{(k)}(y)}[c(r, \theta)-\gamma(r)] d x=0
$$

for all $y \geqq 0$. Therefore by Theorem 2.1

$$
\int_{G_{(k)}} c v_{1}^{2} d x=\int_{G_{(k)}} \gamma v_{1}^{2} d x
$$

for $k=1,2, \cdots$. 
Consider now the eigenvalue problem

$$
\begin{aligned}
\Delta u+c(x) u+\lambda u & =0 \text { in } G_{(k)} \\
u & =0 \text { on } \partial G_{(k)} .
\end{aligned}
$$

By the standard variational characterization of $\lambda_{1}$ we have

$$
\begin{aligned}
\lambda_{1} & =\min _{u \in \Phi} \frac{\int_{G_{(k)}}\left(|\nabla u|^{2}-c u^{2}\right) d x}{\int_{G_{(k)}} u^{2} d x} \leqq \frac{\int_{G_{(k)}}\left(\left|\nabla v_{1}\right|^{2}-c v_{1}^{2}\right) d x}{\int_{\sigma_{(k)}} v_{1}^{2} d x} \\
& =\frac{\int_{G_{(k)}}\left(\left|\nabla v_{1}\right|^{2}-\gamma v_{1}^{2}\right) d x}{\int_{G_{(k)}} v_{1}^{2} d x}=0,
\end{aligned}
$$

where $\Phi$ denotes the class of "admissible" functions for (2.6). Therefore $\lambda_{1} \leqq 0$ and, by classical variational techniques, for each $G_{(k)}$ there exists a subdomain $G_{(k)}^{\prime} \leqq G_{(k)}$ for which the eigenvalue problem

$$
\begin{aligned}
\Delta u+c u+\lambda^{\prime} u=0 & & \text { in } G_{(k)}^{\prime} \\
u=0 & & \text { on } \partial G_{(k)}^{\prime}
\end{aligned}
$$

satisfies $\lambda_{1}^{\prime}=0$. This completes the proof.

An application of the Sturmian comparison theorem for elliptic equations [7] yields the following result.

COROLlary 2.3. If (2.3) is oscillatory at $r=\infty$ and $u(x)$ is a solution of (2.1), then $u(x)$ has a zero in $E_{R}$ for every $R>0$.

3. The case $n=2$. In case $n=2$ equation (2.3) becomes

$$
\frac{d}{d r}\left(r \frac{d v}{d r}\right)+r \gamma(r) v=0
$$

and the Leighton oscillation criterion [8] asserts that (3.1) is oscillatory at $r=\infty$ if

$$
\int_{0}^{\infty} r \gamma(r) d r=+\infty
$$

Recalling the definition of $\gamma(r)$ we have

$$
\int_{0}^{\infty} r \gamma(r) d r=\frac{1}{2 \pi} \int_{0}^{\infty}\left[\int_{0}^{2 \pi} c(r, \theta) d \theta\right] r d r=\frac{1}{2 \pi} \iint_{E^{2}} c(x, y) d x d y .
$$

These observations together with Theorem 2.2 yield 


$$
\iint_{E^{2}} c(x, y) d x d y=+\infty
$$

then $\Delta u+c u=0$ is nodally oscillatory in $E^{2}$.

The transformation $t=\ln r$ transforms equation (3.1) into

$$
\frac{d^{2} v}{d t^{2}}+e^{2 t} \gamma\left(e^{t}\right) v(t)=0
$$

and leaves oscillation invariant. A result of Hille [5] asserts that (3.4) is oscillatory if

$$
\frac{1}{4}<\liminf _{t \rightarrow \infty} t \int_{t}^{\infty} e^{2 s} \gamma\left(e^{s}\right) d s .
$$

Using the change of variables $s=\ln r$ and equation (3.3) we obtain

THEOREM 3.2. If

$$
\frac{\pi}{2}<\liminf _{r \rightarrow \infty}(\ln r) \int_{E_{r}} \int c(x, y) d x d y
$$

then $\Delta u+c u=0$ is nodally oscillatory in $E^{2}$.

Nehari [9] shows that if $\gamma(r) \geqq 0$ and

$$
\limsup _{t \rightarrow \infty} t \int_{t}^{\infty} e^{2 s} \gamma\left(e^{s}\right) d s=\infty
$$

then

$$
\frac{d^{2} v}{d t^{2}}+\lambda e^{2 t} \gamma\left(e^{t}\right) v(t)=0
$$

is oscillatory for all positive $\lambda$. Using Nehari's result, the change of variables $s=\ln r$, and Theorem 2.2 , we obtain

THEOREM 3.3. If $c(x, y) \geqq 0$ and

$$
\limsup _{r \rightarrow \infty}(\ln r) \int_{E_{r}} \int c(x, y) d x d y=\infty
$$

then $\Delta u+\lambda c(x, y) u=0$ is nodally oscillatory for all positive $\lambda$.

4. The case $n>2$. In the case $n>2$ equation (2.3) does not satisfy the conditions of the Leighton oscillation criterion [8]. However this difficulty can be overcome by making the oscillation-preserving transformation $\varphi(r)=r^{(n-1) / 2} v(r)$. Equation (2.3) then becomes

$$
\varphi^{\prime \prime}+\left[\gamma(r)-(n-1)(n-3) / 4 r^{2}\right] \varphi=0 .
$$


The Leighton oscillation criterion applied to (4.1) together with Theorem 2.2 yields

THEOREM 4.1. If

$$
\int^{\infty} \gamma(r) d r=\infty
$$

then $\Delta u+c u=0$ is nodally oscillatory in $E^{n}$.

THEOREM 4.2. If

$$
\frac{(n-2)^{2}}{4}<\liminf _{r \rightarrow \infty} r^{2} \gamma(r)
$$

then $\Delta u+c u=0$ is nodally oscillatory in $E^{n}$.

Proof. Condition (4.2) implies that there exist constants $r_{0}$ and $k$ such that

$$
\frac{(n-2)^{2}}{4}<k<r^{2} \gamma(r) \text { for } r_{0}<r .
$$

Thus the Euler equation $\left(r^{n-1} v^{\prime}\right)^{\prime}+k r^{n-3} v=0$ is oscillatory and (2.3) is oscillatory by Sturm's comparison theorem.

Theorem 4.2 improves similar results by Glazman [2] and Headley [4]. We shall now extend Theorem 3.2 to the case $n>2$. A simple application of Hille's classical result (3.4) to equation (4.1), together with Theorem 2.2, yields

Theorem 4.3. If

$$
\frac{(n-2)^{2}}{4}<\liminf _{r \rightarrow \infty} r \int_{r}^{\infty} \gamma(r) d r
$$

then $\Delta u+c u=0$ is nodally oscillatory in $E^{n}$.

Theorem 4.3 improves a result of Swanson [10].

Using (3.5) and equation (4.1) we obtain

THEOREM 4.4. If

$$
\limsup _{r \rightarrow \infty} r \int_{r}^{\infty} \gamma(r) d r=
$$

then $\Delta u+\lambda c u=0$ is nodally oscillatory in $E^{n}$ for all positive $\lambda$.

5. A more general equation. In this section we shall sketch 
the proof of oscillation criteria for the more general elliptic equation

$$
\sum_{i, j=1}^{n} \frac{\partial}{\partial x_{j}}\left(a_{i j}(x) \frac{\partial u}{\partial x_{i}}\right)+c(x) u=0
$$

in $E^{n}$. We denote by $N(r, \theta)$ the largest eigenvalue of the matrix $A(x)=\left(a_{i j}(x)\right)$ at $x=(r, \theta)$ and define

$$
\nu(r)=\frac{1}{\sum_{n}} \int_{\Omega} N(r, \theta) d \theta .
$$

By classical variational principles the first eigenvalue of

$$
\begin{aligned}
& \sum_{i, j=1}^{n} \frac{\partial}{\partial x_{j}}\left(a_{i j} \frac{\partial}{\partial x_{i}}\right)+c(x) u+\lambda u=0 \quad \text { in } G \\
& u=0 \quad \text { on } \partial G
\end{aligned}
$$

is no larger than the first eigenvalue of

$$
\begin{aligned}
& \nabla \cdot(N(r, \theta) \nabla u)+c(r, \theta) u+\lambda u=0 \text { in } G \\
& u=0 \text { on } \partial G \text {. }
\end{aligned}
$$

Thus to show that (5.1) is nodally oscillatory in $E^{n}$ it is sufficient to show that (5.2) is nodally oscillatory. To that end, consider the eigenvalue problem

$$
\begin{aligned}
\nabla \cdot(\nu(r) \nabla v)+\gamma(r) v+\mu v & =0 & & \text { in } G \\
v & =0 & & \text { on } \partial G
\end{aligned}
$$

and the related elliptic equation

$$
\nabla \cdot(\nu(r) \nabla v)+\gamma(r) v=0
$$

where $\gamma(r)$ is defined as in $\S 2$. Equation (5.4) has solutions $v(r)$ which are independent of $\theta$ and can be found by solving the ordinary differential equation

$$
\frac{d}{d r}\left(r^{n-1} \nu(r) \frac{d v}{d r}\right)+r^{n-1} \gamma(r) v=0
$$

THEOREM 5.1. If the ordinary differential equation (5.5) is oscillatory at $r=\infty$, then (1.1) is nodally oscillatory in $E^{n}$.

Proof. As in the proof of Theorem 2.2 let $r_{1}<r_{2}<\cdots$ be the zeros of a solution $v_{1}(r)$ and consider the domain

$$
G_{(k)}=\left\{(r, \theta): r_{k}<r<r_{k+1}\right\} .
$$

Then $v_{1}(r)$ is an eigenfunction of (5.3) corresponding to $\mu_{1}=0$. Since 
the level curves (surfaces) of $v_{1}$ and of $\nabla v_{1}=\partial v / \partial r$ are circles (spheres) it follows as before that

$$
\int_{G_{(k)}} \gamma v_{1}^{2} d x=\int_{G_{(k)}} c v_{1}^{2} d x
$$

and

$$
\int_{G_{(k)}} N\left|\nabla v_{1}\right|^{2} d x=\int_{G_{(k)}} \nu\left|\nabla v_{1}\right|^{2} d x
$$

for $k=1,2, \cdots$. The first eigenvalue of (5.2) is given by

$$
\begin{aligned}
\lambda_{1} & =\min _{u \in \Phi} \frac{\int_{G_{(k)}}\left(N|\nabla u|^{2}-c u^{2}\right) d x}{\int_{G_{(k)}} u^{2} d x} \leqq \frac{\int_{G_{(k)}}\left(N\left|\nabla v_{1}\right|^{2}-c v_{1}^{2}\right) d x}{\int_{\sigma_{(k)}} v_{1}^{2} d x} \\
& =\frac{\int_{G_{(k)}}\left(\nu\left|\nabla v_{1}\right|^{2}-\gamma v_{1}^{2}\right) d x}{\int_{G_{(k)}} v_{1}^{2} d x}=\mu_{1}=0 .
\end{aligned}
$$

Therefore $\lambda_{1} \leqq 0$, and the remainder of the proof follows as in Theorem 2.2.

6. Unbounded domains. In this section we shall study the oscillatory behavior of solutions of $\nabla u+c u=0$ in unbounded domains $G$. For the sake of simplicity we shall restrict our attention to the case $n=2$, even though some of the results clearly generalize to $E^{n}$.

Consider first a conical domain

$$
G=\left\{(r, \theta) \in E^{2}: \alpha<\theta<\beta\right\}
$$

and suppose that $c(x)$ is continuous in $G$. Defining

$$
\gamma(r)=\frac{1}{\beta-\alpha} \int_{\alpha}^{3} c(r, \theta) d \theta,
$$

we shall obtain oscillation criteria for certain solutions of $\Delta u+c u=0$ in $G$. If the ordinary differential equation

$$
\frac{d}{d r}\left(r \frac{d v}{d r}\right)+r \gamma(r) v=0
$$

is oscillatory at $r=\infty$, then $v(r)$ is also a solution of

$$
\Delta v+\gamma(r) v=0 \text { in } G
$$

satisfying $\partial v / \partial \nu=0$ on $\partial G$, where $\partial v / \partial \nu$ denotes the exterior normal 
derivative. Furthermore if $v_{1}(r)$ is a solution of (6.1) with zeros at $r_{1}<r_{2}<\cdots, \lim _{k \rightarrow \infty} r_{k}=\infty$, then $v_{1}(r)$ defines a sequence of domains

$$
G_{(k)}=\left\{(r, \theta): r_{k}<r<r_{k+1} ; \alpha<\theta<\beta\right\}
$$

in which the first eigenvalue of

$$
\begin{array}{rlrl}
\Delta v+\gamma(r) v+\mu v & =0 & & \text { in } G_{(k)} \\
v & =0 & & \text { on } \partial G_{(k)} \cap\left\{r: r=r_{k} \text { or } r=r_{n+1}\right\} \\
\frac{\partial v}{\partial \nu}=0 & & \text { on } \partial G_{(k)} \cap\{\theta: \theta=\alpha \text { or } \theta=\beta\}
\end{array}
$$

satisfies $\mu_{1}=0$ for $k=1,2, \cdots$.

By an argument analogous to that used in Theorem 2.2 one concludes that the first eigenvalue of

$$
\begin{aligned}
\Delta u+c(x) u+\lambda u & =0 \text { in } G_{(k)} \\
u & =0 \text { on } \partial G_{(k)} \cap\left\{r: r=r_{k} \text { or } r=r_{k+1}\right\} \\
\frac{\partial u}{\partial \nu} & =0 \text { on } \partial G_{(k)} \cap\{\theta: \theta=\alpha \text { or } \theta=\beta\}
\end{aligned}
$$

satisfies $\lambda_{1} \leqq 0$ for $k=1,2, \cdots$. An application of the Sturmian comparison theorem of [7] yields the following result.

Theorem 6.1. If $u(x)$ is a solution of $\Delta u+c u$ in the cone $G$ satisfying $\partial u / \partial \nu=0$ on $\partial G$, and if (6.1) is oscillatory at $r=\infty$, then $u(x)$ has a zero in $G_{R}$ for every $R>0$.

THEOREM 6.2. If $u(x)$ is a solution of $\Delta u+c u=0$ in the cone $G$ satisfying $\partial u / \partial \nu=0$ on $\partial G$, and if

$$
\iint_{G} c(x, y) d x d y=+\infty
$$

then $u(x)$ has a zero in $G_{R}$ for every $R>0$.

Proof. From the definition of $\gamma\left(r^{\circ}\right)$,

$$
\int_{0}^{\infty} r \gamma(r) d r=\frac{1}{\beta-\alpha} \int_{0}^{\infty}\left[\int_{\alpha}^{\beta} c(r, \theta) d \theta\right] r d r=\frac{1}{\beta-\alpha} \iint_{G} c(x, y) d x d y .
$$

By the Leighton oscillation criterion [8], the fact that $\int_{0}^{\infty} r \gamma(r) d r=+\infty$ implies that (6.1) is oscillatory at $r=\infty$. An application of Theorem 6.1 now completes the proof.

In $E^{2}$ we can establish oscillation criteria in more general domains 
by means of conformal mapping. As an example of such results, suppose $\Gamma$ is an unbounded domain in $E^{2}$ and that

$$
\xi=\xi(x, y) ; \eta=\eta(x, y)
$$

defines a conformal map of $\Gamma$ onto the cone $G$. Assuming that the Jacobian $J(\xi, \eta / x, y)$ is bounded assures that the singularity at $\infty$ is preserved under such a map. Furthermore, solutions of

$$
\begin{aligned}
u_{x x}+u_{y y}+c(x, y) u=0 & \text { in } \Gamma \\
\frac{\partial u}{\partial \nu}=0 & \text { on } \partial \Gamma
\end{aligned}
$$

are transformed into solutions of

$$
\begin{aligned}
u_{\hat{\xi}}+u_{\eta \eta}+C(\xi, \eta) J\left(\frac{x, y}{\xi, \eta}\right) & =0 \quad \text { in } G \\
\frac{\partial u}{\partial \nu} & =0 \text { on } \partial G
\end{aligned}
$$

where $C(\xi, \eta)=c(x(\xi, \eta), y(\xi, \eta))$. Since

$$
\iint_{\Gamma} c(x, y) d x d y=\iint_{G} C(\xi, \eta) J\left(\frac{x, y}{\xi, \eta}\right) d \xi d \eta,
$$

the condition

$$
\iint_{\Gamma} c(x, y) d x d y=+\infty
$$

assures that solutions of

$$
\begin{gathered}
\Delta u+c u=0 \text { in } \Gamma \\
\frac{\partial u}{\partial \nu}=0 \text { on } \partial \Gamma
\end{gathered}
$$

will have zeros in $\Gamma_{R}$ for all $R>0$.

Added in revision. The authors have learned of some recent work of E. Noussair, to appear in the Journal of Differential Equations, which establishes related results for elliptic equations of even order. In particular, our Theorem 3.1 is a special case of Noussair's results. We note, however, that Noussair's techniques are different, requiring substantial machinery of a variational nature, and that our techniques can also be extended to deal with the case of even order elliptic equations. 
Added in Proof. Noussair's paper has since appeared in the $J$. Differential Equations, 10 (1971), 100-111. C. A. Swanson has also shown us a shorter proof of Theorem 2.2 based on a paper by Swanson and Headley in the Pacific Journal of Mathematics, 27 (1968), 501506. This proof will appear in the Canadian Mathematical Bulletin.

\section{REFERENCES}

1. D. O. Banks, An integral inequality, Proc. Amer. Math. Soc., 14 (1963), 823-828.

2. I. M. Glazman, Direct Methods of Qualitative Spectral Analysis of Singular Differential Operators, (Israel Program for Scientific Translations), Davey, New York, 1965.

3. V. B. Headley and C. A. Swanson, Oscillation criteria for elliptic equations, Pacific J. Math., 27 (1968), 501-506.

4. V. B. Headley, Some oscillation properties of selfadjoint elliptic equations, Proc. Amer. Math. Soc., 21 (1970), 824-829.

5. E. Hille, Non-oscillation theorems, Trans. Amer. Math. Soc., 64 (1948), 234-252.

6. K. Kreith, Oscillation theorems for elliptic equations, Proc. Amer. Math. Soc., 15 (1964), 341-344.

7. —, A strong comparison theorem for selfadjoint elliptic equations, Proc. Amer. Math. Soc., 19 (1968), 989-990.

8. W. Leighton, On selfadjoint differential equations of second order, J. London Math. Soc., 27 (1952), 37-47.

9. Z. Nehari, Oscillation criteria for second-order linear differential equations, Trans. Amer. Math. Soc., 85 (1957), 428-445.

10. C. A. Swanson, Nonoscillation criteria for elliptic equations, Canad. Math. Bull., 12 (1969), 275-280.

Received February 17, 1971 and in revised form May 4, 1971.

UNIVERSity OF CALIFORNIA, DAVIS

AND

VANDERBILT UNIVERSITY 



\title{
PACIFIC JOURNAL OF MATHEMATICS
}

\author{
EDITORS
}

H. SAMELSON

Stanford University

Stanford, California 94305

C. R. HOBBY

University of Washington

Seattle, Washington 98105

\section{J. DugundJI}

Department of Mathematics

University of Southern California

Los Angeles, California 90007

RICHARD ARENS

University of California

Los Angeles, California 90024

\section{ASSOCIATE EDITORS}
E. F. BeCKeNBACH
B. H. NeUmanN
F. WoLF
K. YoSHIDA

\section{SUPPORTING INSTITUTIONS}

\author{
UNIVERSITY OF BRITISH COLUMBIA \\ CALIFORNIA INSTITUTE OF TECHNOLOGY \\ UNIVERSITY OF CALIFORNIA \\ MONTANA STATE UNIVERSITY \\ UNIVERSITY OF NEVADA \\ NEW MEXICO STATE UNIVERSITY \\ OREGON STATE UNIVERSITY \\ UNIVERSITY OF OREGON \\ OSAKA UNIVERSITY
}

\author{
UNIVERSITY OF SOUTHERN CALIFORNIA \\ STANFORD UNIVERSITY \\ UNIVERSITY OF TOKYO \\ UNIVERSITY OF UTAH \\ WASHINGTON STATE UNIVERSITY \\ UNIVERSITY OF WASHINGTON

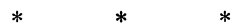 \\ AMERICAN MATHEMATICAL SOCIETY \\ NAVAL WEAPONS CENTER
}

The Supporting Institutions listed above contribute to the cost of publication of this Journal, but they are not owners or publishers and have no responsibility for its content or policies.

Mathematical papers intended for publication in the Pacific Journal of Mathematics should be in typed form or offset-reproduced, (not dittoed), double spaced with large margins. Underline Greek letters in red, German in green, and script in blue. The first paragraph or two must be capable of being used separately as a synopsis of the entire paper. The editorial "we" must not be used in the synopsis, and items of the bibliography should not be cited there unless absolutely necessary, in which case they must be identified by author and Journal, rather than by item number. Manuscripts, in duplicate if possible, may be sent to any one of the four editors. Please classify according to the scheme of Math. Rev. Index to Vol. 39. All other communications to the editors should be addressed to the managing editor, Richard Arens, University of California, Los Angeles, California, 90024.

50 reprints are provided free for each article; additional copies may be obtained at cost in multiples of 50 .

The Pacific Journal of Mathematics is published monthly. Effective with Volume 16 the price per volume (3 numbers) is $\$ 8.00$; single issues, $\$ 3.00$. Special price for current issues to individual faculty members of supporting institutions and to individual members of the American Mathematical Society: $\$ 4.00$ per volume; single issues $\$ 1.50$. Back numbers are available.

Subscriptions, orders for back numbers, and changes of address should be sent to Pacific Journal of Mathematics, 103 Highland Boulevard, Berkeley, California, 94708.

PUBLISHED BY PACIFIC JOURNAL OF MATHEMATICS, A NON-PROFIT CORPORATION

Printed at Kokusai Bunken Insatsusha (International Academic Printing Co., Ltd.), 270, 3-chome Totsuka-cho, Shinjuku-ku, Tokyo 160, Japan. 


\section{Pacific Journal of Mathematics}

\section{Vol. 41, No. $3 \quad$ BadMonth, 1972}

George E. Andrews, Two theorems of Gauss and allied identities proved arithmetically.................................. 563

Stefan Bergman, On pseudo-conformal mappings of circular domains . . . . 579

Beverly L. Brechner, On the non-monotony of dimension ............ 587

Richard Anthony Brualdi and John H. Mason, Transversal matroids and Hall's theorem .................................... 601

Philip Throop Church and James Timourian, Differentiable maps with

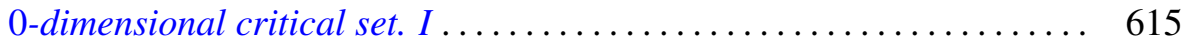

John H. E. Cohn, Squares in some recurrent sequences ............. 631

Robert S. Cunningham, Edgar Andrews Rutter and Darrell R. Turnidge, Rings of quotients of endomorphism rings of projective modules ......

Eldon Dyer and S. Eilenberg, An adjunction theorem for locally equiconnected spaces................................... 669

Michael W. Evans, On commutative P. P. rings................. 687

Ronald Lewis Graham, Hans Sylvain Witsenhausen and Hans Zassenhaus, On tightest packings in the Minkowski plane ..................

Stanley P. Gudder, Partial algebraic structures associated with

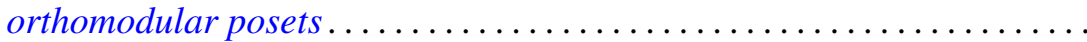

Karl Edwin Gustafson and Gunter Lumer, Multiplicative perturbation of

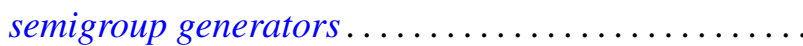

Kurt Kreith and Curtis Clyde Travis, Jr., Oscillation criteria for selfadjoint elliptic equations...

Lawrence Louis Larmore, Twisted cohomology theories and the single obstruction to lifting...........................

Jorge Martinez, Tensor products of partially ordered groups . . .

Robert Alan Morris, The inflation-restriction theorem for Amitsur cohomology ...

Leo Sario and Cecilia Wang, The class of $(p, q)$-biharmonic functions ...

Manda Butchi Suryanarayana, On multidimensional integral equations of

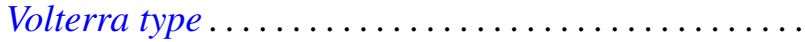

